\title{
Eat more vegetables daily
}

\section{Editorial}

If consuming your recommended two to three cups of vegetables every day feels like a chore, it's obvious you've yet to tap into the artful, enchanting and exquisite potential of the edible plant. A serving of vitamin-rich, nutrient-dense produce doesn't have to be consumed through a sad Tupperware's worth of wilted iceberg, or a measly carrot stick used solely as a vessel for unhealthy ranch dip. No, when treated right, vegetables can be the extraordinary main event of your meal. Amp up the volume of a carb dish by tossing in some broccoli. Or swap pasta for spiraled veggies-turned-noodles, to cut back on calories and boost the nutrition of the dish.

A new study estimates that Canada wastes 3.3 billion \$CAN yearly because its citizens dont eat enough fruit and veggies. Just imagine what that sum would be for the US.

Super Bowl LI featured some great ads, quite a few of them for food. Whose advertising? McDonalds, KFC, Snickers, Skittles, and yes, to balance all that sugar fat and salt there were lonely Avocados from Mexico.

Junk food ad spend is enormous -5 million for a 30 second ad in the 2017 Super Bowl and snack and fast-food companies spend billions each year to convince Americans to consume their merchandise.

Surprisingly, when it comes to fruits and veggies were wasting billions by not eating them.

Many chronic diseases such as diabetes, heart disease and cancer are attributable, at least in part, to diet and lifestyle. Other modifiable lifestyle factors - exercise, obesity and smoking for instance - are addressed often, and their economic burden is calculated. Estimates of the price of not eating your fruits and veggies are hard to find.

In a new study in Public Health Nutrition, Canadian researchers, led by John Ekwaru and Paul Veugelers looked at chronic diseases in which fruits and veggie intake significantly reduces disease burden across many studies. After assembling the established estimates of the risk of inadequate vegetables and fruit on these chronic diseases, they found that the 80 percent of women and 89 percent of men in Canada eat inadequate amounts of veggies and fruit. Their most conservative estimate of the price of not eating your fruits and veggies in Canada is 3.3billion \$CAN yearly, a third of which is in direct health-care costs and two-thirds is indirect costs due to people being too sick to go to work.
Volume 8 Issue I - 2018

\section{George Grant \\ World organization of Natural Medicine, Richmond Hill, Canada}

Correspondence: George Grant, World organization of Natural Medicine, Richmond Hill, Canada,

Email drgrantwellness@gmail.com

Received: January 05, 2018 | Published: January II, 2018

And this is in Canada. The US population is almost ten times larger and healthcare and drug costs in the US are far steeper. Healthy food is a good investment. It's rather heartless to measure human disease in dollars. Healthcare and productivity costs are dwarfed by the price in human pain and suffering. But this economic calculation is valuable when it comes to investing funds in public health.

When you look at it this way, it becomes evident that helping people eat better isn't just the just and humane thing to do; it's a solid financial investment, with very good returns, even if all you care about it the bottom line in dollars and cents.

Making healthy food accessible should be a public health priority. The take home message from this study, for us, as individuals, is very simple. When you are out shopping for food, the price at the grocer doesn't always reflect the true cost. When you are buying healthy food you are investing in your own health. When you buy junk food, its price at the cash register is a fraction of what it will really cost you down the line. The cheapest foods and 1-dollar menus are actually very pricey and too expensive to even consider.

\section{Acknowledgements}

None.

\section{Conflict of interest}

The author declares no conflict of interest. 